\title{
Paracetamol poisoning below toxic level causing liver damage in a fasting adult
}

W K B Kasun Fernando ${ }^{1}$ and P L Ariyananda ${ }^{2}$

\section{Introduction}

In many countries, paracetamol ranks at the top of all known poisoning agents implicated in accidental or intentional poisoning [1]. In general, liver injury caused by drugs is known to be either type A "dose dependent" (intrinsic toxicity) or type B idiosyncratic. Perhaps with the exception of single high dose of drug induced liver injury, most drug induced liver injury (DILI) cases evaluated in clinical practice are considered as idiosyncratic [2].

Hepatotoxicity is the major manifestation of paracetamol poisoning, although kidneys and heart may also be affected in severe poisoning [3]. N-acetylcysteine prevents toxicity if given within the first eight hours but is also of benefit in patients presenting late or with established hepatotoxicity.

\section{Case report}

A 23-year old unmarried woman was admitted to the University Medical Unit of the Teaching Hospital, Karapitiya (THK) on February 26, 2008 with a history of taking an overdose of paracetamol. The patient had been working as a sales assistant in a shoe shop until two days prior to admission, in apparent good health, both mentally and physically. She had not received any treatment at the time she presented to us. She denied use of recreational drugs, alcohol or tobacco. There was no history of blood transfusion, hepatitis or other chronic illnesses. She had occasionally used paracetamol without any adverse effects.

During the 24 hours preceding ingestion of paracetamol, she was starving as a self-imposed punishment. Then she had ingested 12 tablets $(6 \mathrm{~g})$ of paracetamol. There was no spontaneous vomiting. Patient was brought to THK 3 hours after ingestion. On admission to hospital there were no abnormal physical findings. Her body weight was $42 \mathrm{~kg}$ and the BMI was 19.8. The amount of paracetamol ingested was $143 \mathrm{mg} / \mathrm{kg}$ body weight. Because the toxic dose is $150 \mathrm{mg} / \mathrm{kg}$ it was decided not to give $\mathrm{N}$-acetyl cysteine (NAC). However, the 4 hours postoverdose plasma paracetamol level was $78 \mathrm{mg} / \mathrm{l}$.
Next day she was found to have jaundice and was started on NAC. NAC was started 22 hours postingestion. Patient complained of loss of appetite and nausea but no liver tenderness was elicited. Serum bilirubin was noted to have come down on day 6. Patient was discharged on day 8 . On discharge, the patient was clinically normal and INR was 1 . The laboratory results are shown in Table 1.

Table 1

\begin{tabular}{lcccccc}
\hline TEST & $\begin{array}{c}\text { Day } \\
1\end{array}$ & $\begin{array}{c}\text { Day } \\
2\end{array}$ & $\begin{array}{c}\text { Day } \\
3\end{array}$ & $\begin{array}{c}\text { Day } \\
4\end{array}$ & $\begin{array}{c}\text { Day } \\
5\end{array}$ & $\begin{array}{c}\text { Day } \\
6\end{array}$ \\
\hline SGPT & & & $250 \mathrm{u} / 1$ & & $305 \mathrm{u} / 1$ & $120 \mathrm{u} / 1$ \\
SGOT & & & $206 \mathrm{u} / 1$ & & $163 \mathrm{u} / 1$ & $303 \mathrm{u} / 1$ \\
INR & 1.7 & 1.4 & 1.2 & 2.5 & 1.2 & 1.1 \\
$\begin{array}{l}\text { Total } \\
\text { bilirubin }\end{array}$ & & & & & & \\
$\begin{array}{l}\text { Direct } \\
\text { bilirubin }\end{array}$ & & & $5.8 \mathrm{mg} / \mathrm{dl}$ & & & $1.8 \mathrm{mg} / \mathrm{dl}$ \\
Urobilinogen & & & & & & \\
& & & & & & \\
\hline
\end{tabular}

\section{Discussion}

$78 \mathrm{mg} / \mathrm{l}$ of 4 hours post-overdose plasma paracetamol level is well below the toxic level even with risk factors. But history and examination findings were compatible with liver cell damage. We therefore suggest that the period of 24 hours of fasting would have been responsible for liver cell damage even at this sub-toxic dose of paracetamol.

During metabolism and elimination, the minor pathways involving P450 enzymes account only for about $5-10 \%$ of paracetamol metabolism in therapeutic use. These lead to production of a toxic metabolite, N-acetylp-benzoquinonimine (NAPQI). This conjugates with glutathione and is excreted as a non-toxic conjugate in urine. When glutathione is depleted, this reactive metabolite binds covalently to hepatic macromolecules and leads to cell death $[3,4,5]$.

${ }^{1}$ South Asian Clinical Toxicology Research Collaboration (SACTRC), Faculty of Medicine, University of Peradeniya, and ${ }^{2}$ Department of Medicine, Faculty of Medicine, University of Ruhuna, Sri Lanka.

Correspondence: PLA, e-mail: <ariyananda@sltnet.lk>. Received 14 May and revised version accepted 11 December 2008. Competing interests: none declared. 
Even though there is no evidence to support the assumption that depletion of glutathione due to fasting will influence DILI in paracetamol overdose [5], there are several variables such as chronic ethanol misuse, use of enzyme-inducing drugs, prolonged fasting and dehydration that may have a causative role in hepatic injury. These "risk factors" are thought to increase the metabolism of paracetamol to the toxic metabolite NAPQI via induction of mixed function oxidases, or decrease hepatocellular glutathione stores, or both [5]. Hepatotoxicity with certain medications such as nitrofurantoin, chlorpromazine, tetracycline, halothane, and diclofenac has been reported more frequently in women [7]. Female sex along with hepatocellular liver damage on admission is suggested to be a risk factor for development of fulminant liver failure [6,7]. The fact that our patient is a female may have made her more vulnerable to DILI.

This case report illustrates that hepatocellular damage could occur even with a 'sub-toxic' dosage of paracetamol in vulnerable patients. It is likely that prolonged fasting has made the patient vulnerable in this instance. If more patients with hepatocellular damage following 'subtoxic' doses of paracetamol overdose in the backdrop of prolonged fasting are reported in the future, we may have to consider repositioning the 'risk line' at a lower level in the Rumack/Matthew Paracetamol Nomogram, under certain circumstances.

\section{Acknowledgements}

We acknowledge the help of Professor Andrew Dawson, Programme Director of the SACTRC for logistical support and Ms. Fathima Shihana Salahudeen, postgraduate research student of the SACTRC for estimating the paracetamol level.

\section{References}

1. Mohd Zain Z, Fatherlrahman AI. Characteristics and outcomes of paracetamol poisoning cases at General Hospital in Northern Malaysia. Singapore Medical Journal 2006; 47: $134-7$

2. Gunawan B, Kaplowitz N. Clinical perspectives on xenobiotic induced hepatotoxicity. Drug Metabolism Review 2004; 36: 301-12.

3. https://www.HyperTox2006.com/ accessed 20.04.2008.

4. Roberts DM, Buckley NA. Pharmacokinetics considerations in clinical toxicology. Clinical Evidence 2003; 9: 1554-60.

5. Daly FFS, Fountain JS, Murray L, Graudins A, Buckley NA. Guidelines for the management of paracetamol poisoning in Australia and New Zealand - explanation and elaboration. Medical Journal of Australia 2008; 188: 296-301.

6. Pachkoria K, Lucena MI, Molokhia M, Cueto R. Genetic and molecular factors in drug-induced liver injury. Current Drug Safety 2007; 2: 97-112.

7. Andrade RJ, Lucena MI, Fernandez MC, et al. Spanish group for the study of drug-induced liver disease. Druginduced liver injury: an analysis of 461 incidences submitted to the Spanish registry over a 10-year period. Gastroenterology 2005; 129: 512-21. 